\title{
Study on Strength Damage Evolution Regulation of Sandstone under Cyclic Erosion
}

\author{
Zhigang Meng $\mathbb{D}^{1,2}$ Xuebin Cui $\mathbb{D}^{1},{ }^{1}$ Gan $Q i \mathbb{D}^{3}{ }^{3}$ Tingting Shi $\mathbb{D},{ }^{1}$ and Juan Ma $\mathbb{D}^{3}$ \\ ${ }^{1}$ State Key Laboratory for Geomechanics and Deep Underground Engineering, China University of Mining and Technology (Beijing), \\ Beijing 10083, China \\ ${ }^{2}$ Liaoning Research Institute for Nonferrous Metals, Shenyang 110000, China \\ ${ }^{3}$ China Geological Environmental Monitoring Institute, Beijing 100081, China
}

Correspondence should be addressed to Xuebin Cui; 2587429754@qq.com

Received 4 December 2020; Revised 23 December 2020; Accepted 31 December 2020; Published 15 January 2021

Academic Editor: Feng Xiong

Copyright (C) 2021 Zhigang Meng et al. This is an open access article distributed under the Creative Commons Attribution License, which permits unrestricted use, distribution, and reproduction in any medium, provided the original work is properly cited.

\begin{abstract}
Owing to salt erosion, the sandstone of Yungang Grottoes has widespread weathering diseases. The soluble salt develops reciprocating crystallization pressure under the action of dry and wet cycles to diminish the sandstone strength. Finally, several pore-like and powder-like weathering phenomena are formed. To explore the change in sandstone strength during this process, the sandstone of Yungang Grottoes was taken as the research object. Herein, the uniaxial compression test, XRD test, and other methods were employed to study the samples under different salt erosion cycles. As the number of salt damage cycles increased, the phenomenon of sand particles on the sandstone surface gradually amplified. The compressive strength, tensile strength, and elastic modulus of sandstone decreased with the increase in erosion cycles. The curve was divided into two stages, and the macroscopic and microscopic damage equations of sandstone after erosion were established. During the entire damage process, erosion damage served as the basis of load damage and was affected by different cycles, impacting the development process of load damage. Through the establishment of numerical simulation meso-parameter evolution equations, the PFC2D particle flow model was used to conduct uniaxial simulation tests, and the simulation results were close to the macroscopic test results. Using the particle flow simulation test parameters under salt erosion, the development of the distribution of "displacement-force chain-crack" was analyzed under different salt erosion cycles. These results further revealed the meso-fracture damage characteristics of the Yungang Grottoes sandstone under the action of salt damage and provided a theoretical basis and a novel method for the protection of Yungang Grottoes against weathering.
\end{abstract}

\section{Introduction}

Salt damage is the leading cause of sandstone weathering [1, 2]. When the soluble salt enriches the pores of sandstone, the soluble salt undergoes repeated crystallization under the alternating action of dry and wet cycles. During this process, the reciprocating crystallization pressure is developed. When the crystallization pressure reaches the cementing strength of the cement, numerous microscopic cracks are generated in the sandstone, which leads to falling off of the sand surface $[3,4]$. The calcareous cement in the sandstone simultaneously reacts with the erosion solution to form novel salt products such as gypsum, causing the feldspar and other minerals in the sandstone particles to gradually degrade, causing chemical weathering [5-7]. The role of salt damage occurs simultaneously at the physical and chemical levels and is one of the primary factors that cause weathering on the surface of sandstone cave cultural relics.

The destruction of stone cultural relics due to salt damage is common in various types of grotto heritage sites in China. The stone cultural relics in the cave heritage sites such as Yungang Grottoes, Dazu Rock Carvings, Dunhuang Mogao Grottoes, and Longyou Grottoes are all affected by the salt damage [8-10]. The stone lithology of Yungang Grottoes is feldspar-quartz mixed sandstone cemented with calcium and magnesium. Groundwater penetrates to the surface of the stone sculptures along the cracked channels, and the carried salt (Esophageal salt $\left(\mathrm{MgSO}_{4}\right)$ and gypsum $\left.\left(\mathrm{CaSO}_{4}\right)\right)$ are 
precipitated after water evaporation. They crystallize and gather on the surface of stone sculptures, forming expansion stress on the pores of rocks. Under the repeated action of dry and wet cycles for a long duration, the tensile strength of the surface rock is greatly reduced, gradually forming flakes, pores, and powder weathering, which severely threatens the preservation of the cultural relics of Yungang Grottoes (see Figure 1). Dazu Rock Carvings are located in a typical Sichuan-Chongqing red-bed sandstone area in China. The sandstone has high mud content, large porosity, high water content, high environmental humidity, and low evaporation. All these conditions are conducive to the formation of soluble salt crystals. The salt damage of quality cultural relics is prominent. The main components of salt damage in Mogao Grottoes at Dunhuang are sodium sulfate $\left(\mathrm{Na}_{2} \mathrm{SO}_{4}\right)$, sodium chloride $(\mathrm{NaCl})$, and moderately soluble salt gypsum $\left(\mathrm{CaSO}_{4}\right)$, which are widely distributed in the wall painting materials and adjacent rock and soil layers of the Mogao Grottoes. The role has become the most destructive factor threatening the safety of murals. The sandstone argillaceous cement in Longyou Grottoes contains more montmorillonite. With the participation of soluble salts such as $\mathrm{Na}_{2} \mathrm{SO}_{4} /-$ $\mathrm{NaCl}$, the higher the concentration of $\mathrm{SO}_{4}{ }^{2-}$ and $\mathrm{Cl}^{-}$ produced by the dissolution of clay minerals in water and ion exchange, the more is the production of carbonate minerals and more prominent is the acceleration of sandstone weathering. High soluble salt content in the weathering product reveals the mechanism of this action.

Scholars at home and abroad have conducted extensive research on the physical and mechanical properties of sandstone under salt damage and revealed the damage and failure mechanisms through physical mechanics and theoretical research. Yan et al. [8] (2013) used Glauber's salt $\left(\mathrm{Na}_{2} \mathrm{SO}_{4}\right)$ to perform a degradation simulation test on the Yungang Grotto sandstone and found that in the process of repeated crystallization of soluble salt, the cementation between rock particles is destroyed, porosity of rocks is increased, and the mechanical parameters such as the stiffness and strength of rocks are severely affected. Li et al. [9] (2008) performed Longyou Grottoes sandstone rock and mineral analysis, clay mineral analysis, and water environment analysis and concluded that by setting the $\mathrm{NaCl}$ and $\mathrm{Na} 2 \mathrm{SO} 4$ saturated solutions to simulate the environmental degradation, the weathering rate of Longyou grottoes sandstone was greatly accelerated with the participation of two soluble salts. Steiger [10] conducted a physical simulation test of rock damage on the Glauber's salt $\left(\mathrm{Na}_{2} \mathrm{SO}^{4-} \mathrm{nH}_{2} \mathrm{O}\right)$ system and found that the expansion and extrusion force formed by the Glauber's salt crystals were about 0-40 MPa. At the same time, the lower the temperature, the greater the crystal pressure, and the tensile strength of the rock was generally less than $5 \mathrm{MPa}$. Hence, repeated crystallization of soluble salt is enough to cause rock damage. Theoulakis and Moropoulou [11] demonstrated that the damage caused by salt damage to sandstone had prominent characteristics in different dimensions of physical and mechanical parameters, such as compressive strength, compressive modulus, porosity, pore distribution, and total internal surface area, and its impact was functionally related to a certain extent. Zhou et al. [12] (2020) used a dynamic

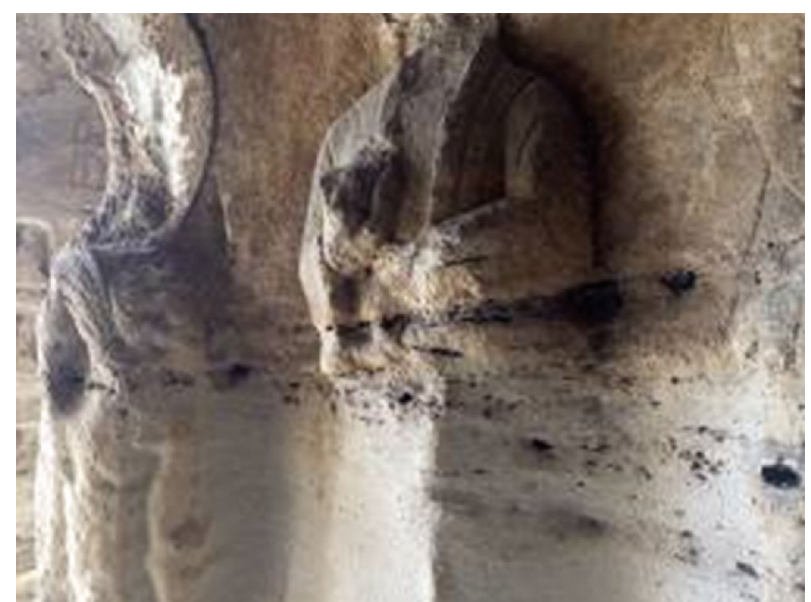

FIGURE 1: Local hole-like weathering in sculpture layer in Yungang Grottoes.

constitutive model to numerically study the mechanical properties of rock materials under cyclic loads of different frequencies and amplitudes. Under the action of multistage cyclic loading, the damage variable increases rapidly in the first stage, then gradually stabilizes, and slowly increases with the rise in loading stress. Zhang et al. [13] (2019) used salt precipitation of high salinity dense sandstone rock matrix porosity, permeability, and permeability stress sensitivity to study the influence of elastic wave velocity. They discovered that the crystallization salt deposited in the micropores, cracks, and clay mineral surface not only reduces the porosity and permeability but also leads to the development of secondary fracture, weakening the rock matrix. Sun et al. [14] (2019) investigated the weathering of rocks under the combined action of freeze-thaw cycles and salt crystallization cycles. They found that the crystallization pressure of salt and the frost heave of ice reduces the cohesive force between the particles and cause the particles to fall off, which is the most important factor causing sandstone damage. Li et al. [15] (2019) performed experimental research on the freezethaw cycles of sandstone in different chemical solutions and used nuclear magnetic resonance technology to study the pore change rules and damage evolution mechanism of sandstone in different chemical solutions. They found that under the coupling effect of chemical solution and freeze-thaw cycles, the porosity of sandstone samples increased with the number of freeze-thaw cycles. Under the effect of chemical solution coupling and freezing and thawing, the pore diameters of all the samples were mainly concentrated in two pore diameters, and the large pore diameter was dominant.

At present, the research on the damage of weathered material is primarily focused on experimental and phenomenon analysis, while the research on the quantitative function relationship between the weathering damage of rock and salt damage and the simulation of the internal damage mechanism is limited [16-18]. This works uses Yungang Grotto sandstone as the research object. Through the study of the composition of the sandstone and environmental water quality analysis, the main types of salt crystals were determined. Using accelerated testing cycle method and circulation of 
TABLE 1: Results of mineral and argillaceous cement composition.

\begin{tabular}{|c|c|c|c|c|c|c|}
\hline \multirow{2}{*}{$\begin{array}{l}\text { Structure } \\
\text { Ingredient }\end{array}$} & \multicolumn{4}{|c|}{ Debris particles } & \multirow{2}{*}{$\begin{array}{c}\text { Interstitial } \\
\text { Chemical cement }\end{array}$} & \multirow{2}{*}{$\begin{array}{c}\text { Tuberculosis } \\
\text { Iron-bearing agglomerates }\end{array}$} \\
\hline & Quartz & Feldspar & Cuttings & Heterobase & & \\
\hline Content/\% & 52 & 42 & 2 & 2 & $1-2$ & $1-2$ \\
\hline
\end{tabular}

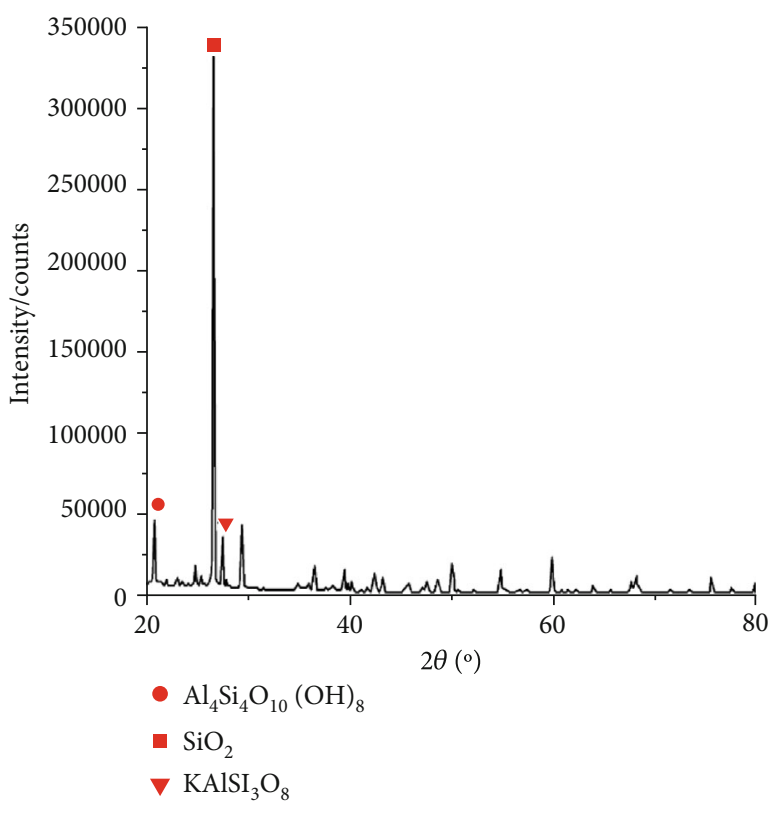

(a)

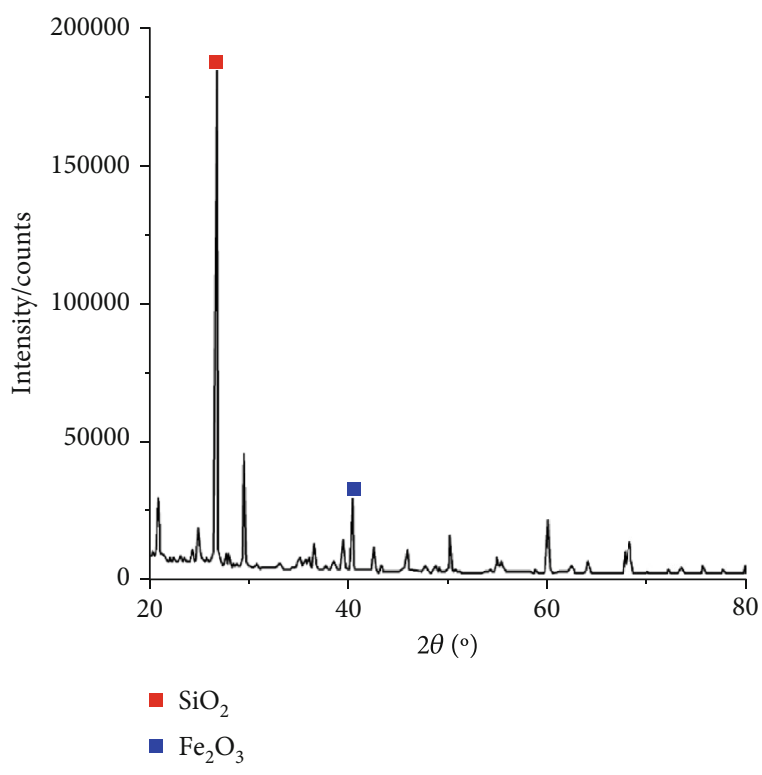

(b)

FIgURe 2: XRD patterns of concretion sandstone. (a) Sandstone matrix. (b) Tuberculosis.

sandstone erosion salt solution immersion test and the determination of the mechanical properties of sandstone after different cycles, the sandstone macroscopic damage and microscopic damage equation were established. The particle flow simulation method further revealed the Yungang Grottoes mesoscopic fracture damage characteristics of sandstone under the action of salt injury. The Yungang Grottoes antiweathering protection path provides a novel method and theoretical basis [19-23].

\section{Salt Erosion Test of Sandstone}

2.1. Sandstone Composition and Cement Analysis. After sampling the Yungang Grottoes sandstone, an X-ray diffractometer and polarizing microscope were employed to analyze the mineral composition and cementation of the rock samples. The results show that the Yungang Grottoes sandstone is primarily medium- and coarse-grained quartz-feldspar sandstone with relatively loose structure and high water permeability. The rock matrix and nodule mineral composition are presented in Table 1. Among them, iron-bearing agglomerates are irregular polyhedrons, which are loose and easily absorb water.

The X-ray diffraction results of sandstone with nodules are shown in Figure 2. The main components of the rock sample matrix were quartz $\left(\mathrm{SiO}_{2}\right)$, feldspar $\left(\mathrm{KAlSi}_{3} \mathrm{O}_{8}\right)$, kaolinite $\left(\mathrm{Al}_{4} \mathrm{Si}_{4} \mathrm{O}_{10}(\mathrm{OH})_{8}\right)$, etc. The cement was carbonate compounds, including $\mathrm{CaCO}_{3}$ and $\mathrm{MgCO}_{3}$. Also, the sample had a huge difference in composition between the core of hematite $\left(\mathrm{Fe}_{2} \mathrm{O}_{3}\right)$ and the matrix.

\subsection{Test Plan and Sample Preparation}

2.2.1. Sample Preparation. The representative sandstone samples from the same formation of Yungang Grottoes were selected, and the sandstone compositions of Yungang Grottoes were compared. The two components were similar in content and belonged to feldspar sandstone. To avoid the error in test results due to the difference in various rock joints, the same rock block was selected to process sandstone specimens and processed into $\Phi 50 \mathrm{~mm} \times 100 \mathrm{~mm}$ cylindrical and $\Phi 50 \mathrm{~mm} \times 20 \mathrm{~mm}$ disc-shaped sandstone specimens. Before analyzing the sandstone specimens, the sandstone specimens were tested for nonmetallic ultrasonic longitudinal wave velocity, and the specimens with large wave velocities were eliminated. The test was divided into two mechanical test categories of compression and tension. Each category was divided into six groups, and each group was set with three parallel test blocks. A total of 36 sandstone test pieces were prepared, and each test piece was grouped and numbered before the test (S0-S30).

2.2.2. Selection of Erosion Liquid. There are several types of soluble salts contained in the rock mass of Yungang Grottoes. However, through verification of relevant domestic and foreign literature, it was found that among different soluble 


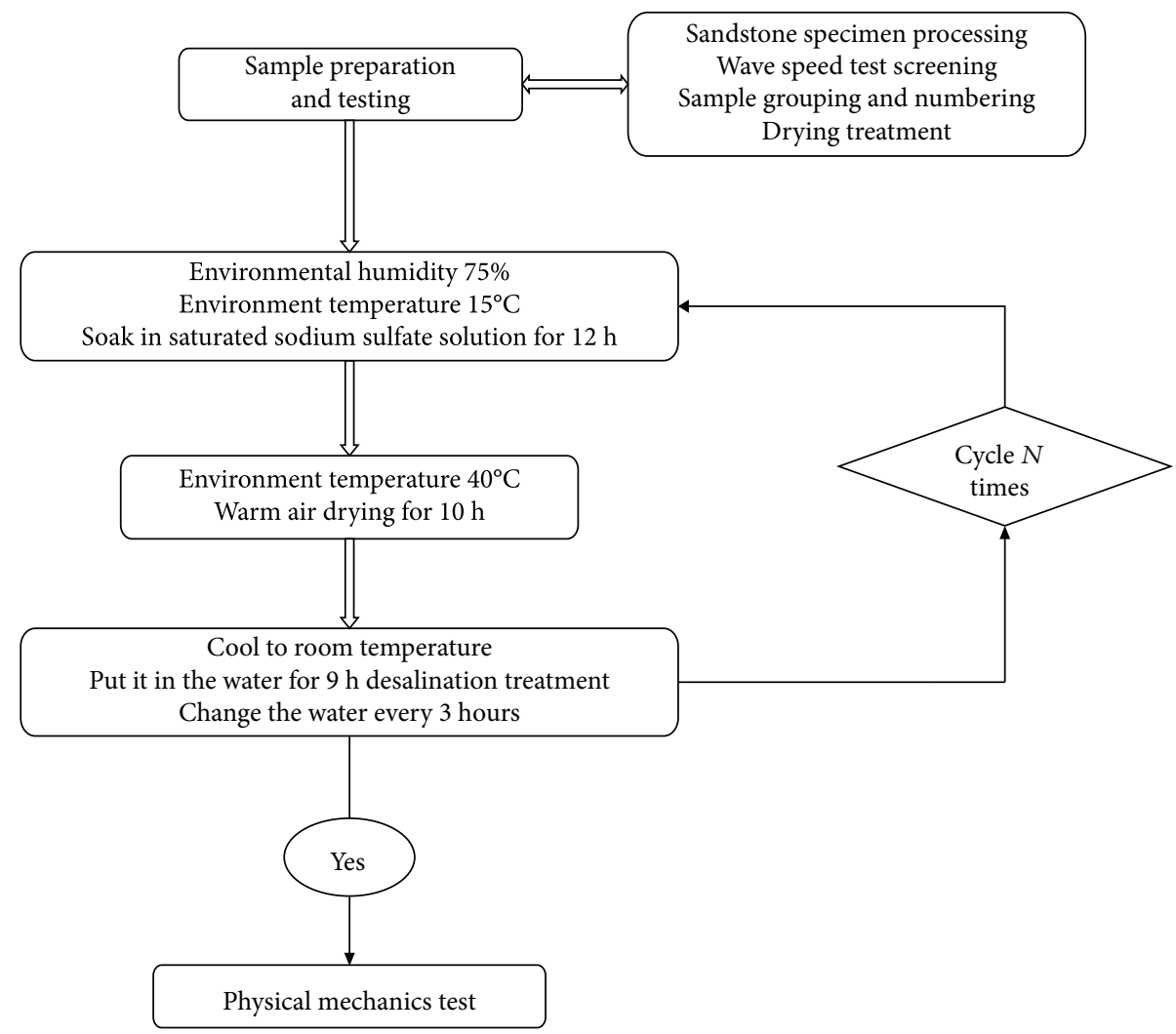

Figure 3: Erosion test operation flowchart.

salts, Glauber's salt $\left(\mathrm{Na}_{2} \mathrm{SO}_{4}\right)$ damaged the rocks more prominently. Glauber's salt not only poses a critical threat to the cultural relics of Yungang Grottoes but also has a great impact on other grottoes in the country. Its destructive effect on building materials has also received widespread attention [24-26]. Therefore, herein, Glauber's salt was selected for testing.

2.2.3. Erosion Test Plan. Before the test, the sandstone specimens were vacuum dried and placed into the prepared erosion liquid for a cyclic erosion test. The erosion cycles were divided into $0,5,10,15,20$, and 30 times. To simulate the low-temperature and high-humidity environment inside the grotto, a standard environmental box was used to accurately control the dry-wet cycle test environment, and the corrosion environment temperature was set to $15^{\circ} \mathrm{C}$ and humidity to $75 \%$.

To simulate the salt damage process of dry and wet cycles owing to the temperature difference between day and night in Yungang Grottoes, each erosion cycle was divided into two links: erosion and drying. The erosion time of a single cycle was $12 \mathrm{~h}$, while the drying time was $10 \mathrm{~h}$. To prevent temperature fluctuations from affecting the sandstone erosion results, the drying temperature refers to the daily ambient temperature of the grotto and was set to $40^{\circ} \mathrm{C}$. After each cycle, the sandstone specimens were taken out and naturally cooled to room temperature. The samples were placed into tap water for desalination treatment, and the water was replaced three times within 9 hours to ensure that all the crystal salts were removed. After completing the cycle of each erosion test, the physical and mechanical properties were measured (see Figure 3).

\subsection{Sandstone Erosion Test Results and Analysis}

2.3.1. Analysis of Apparent Erosion Characteristics. The apparent characteristics of sandstone after different dry-wet cycles are shown in Figure 4 . The results show that as the number of erosion cycle increased, the surface roughness of sandstone gradually amplified, its edges and corners became rounded, the phenomenon of sand falling off gradually intensified, and white powder was formed on the surface. Part of the sandstone specimens after 30 cycles had the most prominent height loss due to erosion. By observing the erosion surface structure of sandstone under an optical microscope, it was found that the growth of $\mathrm{Na}_{2} \mathrm{SO}_{4}$ crystals in the pores of the sandstone produced crystallization stress. When the crystallization stress reached the strength of the cement, numerous microcracks were generated in the sandstone, causing the sand surface to fall off. The calcareous cement in the sandstone simultaneously reacted with the erosion liquid to form salts such as gypsum, and the potassium albite was gradually kaolinized, which had a comprehensive effect on the physical and chemical levels, causing the particle shedding failure mode in sandstone.

2.3.2. Analysis of Quality Loss Characteristics. As the sandstone was damaged by erosion, the quality of the specimens 

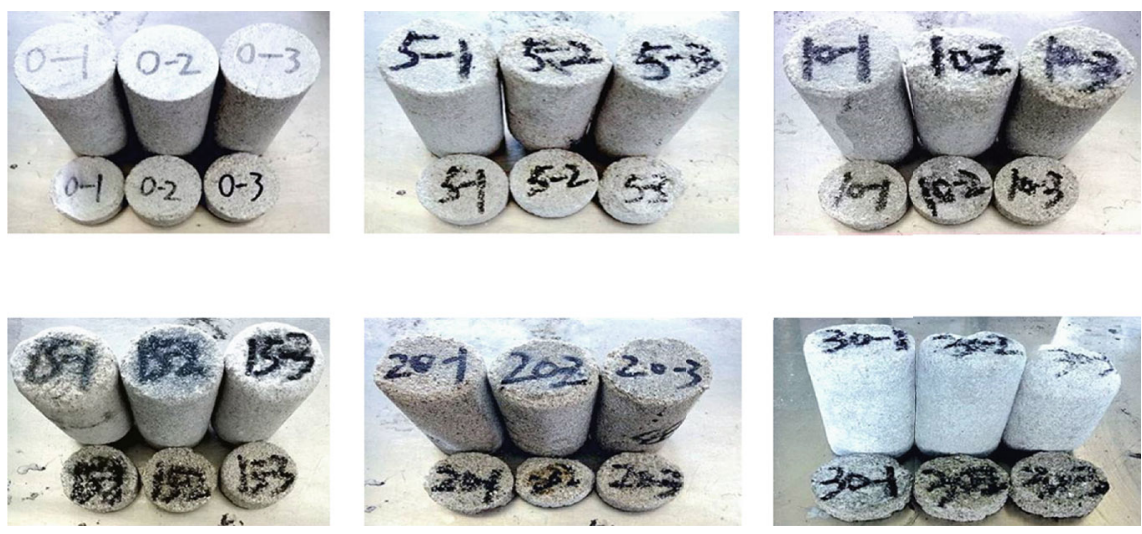

FIGURE 4: Characteristics of apparent erosion damage of sandstone specimens.

decreased with the rise in erosion cycles. This included not only the shedding of particles such as quartz in the sandstone component but also the quality loss due to the erosion reaction product and the dissolution of the sandstone component. To more accurately analyze the quality change law of sandstone in the cyclic erosion process and eliminate the result error due to individual differences, the mass loss rate $R$ is defined to describe the change of sandstone quality with the cyclic erosion cycle:

$$
R=\frac{M_{o}-M_{n}}{M_{o}} \times 100 \%
$$

In the formula, $M_{0}$ is the initial quality of desalted sandstone, while $M_{n}$ is the quality of desalted sandstone after $n$ cycles of erosion.

As shown in Figure 5, the results show that as the erosion period increased, the mass loss rate of each group of specimens gradually amplified. Maximum mass loss occurred when the erosion period was $30 \mathrm{~T}$ and the mass loss was $4.54 \%$. The data shows that Glauber's salt erosion liquid had a significant impact on the quality of sandstone specimens. With the rise in the number of cycles, the mass loss rate of the specimens increased almost linearly, and there was no prominent slowing trend within 30 cycles.

\subsubsection{Sandstone Stress-Strain Curve Characteristics under} Salt Erosion. To study the influence of cyclic erosion on the macromechanical properties of sandstone, uniaxial compression tests were employed to obtain the stress-strain curves under different erosion cycles [27-29]. As shown in Figure 6, the stress-strain curves of each group of sandstones underwent the initial stage, compaction stage, softening stage, and failure stage and still displayed clear brittleness. Comparing the stress-strain curves of different erosion cycles, when approaching the peak stress, there were different degrees of stress readjustment phenomenon, i.e., the phenomenon that the stress dropped sharply and then continued to rise. This was due to the directional damage caused by the immersion erosion of the sandstone, and the degree of damage from the surface and inside was continuously reduced, resulting in an unevenness of the sandstone damage area. When the specimen load reached the peak value, the outside of the specimen was destroyed first, the bearing area was rapidly reduced, and the remaining intact part was loaded again, resulting in a stress readjustment phenomenon. However, under continuous loading, after a short period of resistance, the rock was completely damaged.

\subsubsection{Characteristics of Mechanical Parameters under Salt} Erosion. The compressive strength, tensile strength, and elastic modulus were selected for the macromechanical parameter characterization of the load-bearing capacity of sandstone. Table 2 displays the test results of the sandstone mechanical parameters after different erosion cycles. In the table, $\sigma_{c}, \sigma_{t}$, and $E$ are the compressive strength, tensile strength, and elastic modulus, respectively, while $n$ is the erosion period. When the erosion period was from $0 \mathrm{~T}$ to $30 \mathrm{~T}$, the compressive strength was reduced from $50.42 \mathrm{MPa}$ to 13.39 $\mathrm{MPa}$, a decrease of $73.44 \%$; the tensile strength was reduced from 3.36 MPa to $1.23 \mathrm{MPa}$, a decrease of $63.4 \%$; and the elastic modulus was reduced from $8.41 \mathrm{GPa}$ to $2.50 \mathrm{GPa}$, a decrease of $82.16 \%$. Hence, the mechanical properties of sandstone were greatly lowered, and the erosion fluid had a prominent effect on the mechanical damage of sandstone. As per the test data, the relationship between the mechanical parameters of sandstone and the cycle period was established through regression, and it was found that the relationship between the mechanical parameters and the erosion cycle had a negative exponential relationship. Figure 7 displays the change curve of sandstone mechanical parameters after different erosion cycles. The compressive strength, tensile strength, and elastic modulus of sandstone all decreased with the increase in erosion cycles, and the curve was divided into two stages. The compressive strength and elastic modulus of sandstone attenuated rapidly before $15 \mathrm{~T}$, and the mechanical parameters decreased slowly after $15 \mathrm{~T}$.

\section{Simulation of Compressive Damage Characteristics of Sandstone under Salt Erosion}

3.1. Model Construction and Simulation Plan. Particle flow PFC2D software was used to construct a numerical uniaxial test model randomly generated with the particle radius 
Cycles $(N)$

$\begin{array}{lllllllllllllllll}0 & 2 & 4 & 6 & 8 & 10 & 12 & 14 & 16 & 18 & 20 & 22 & 24 & 26 & 28 & 30 & 32\end{array}$

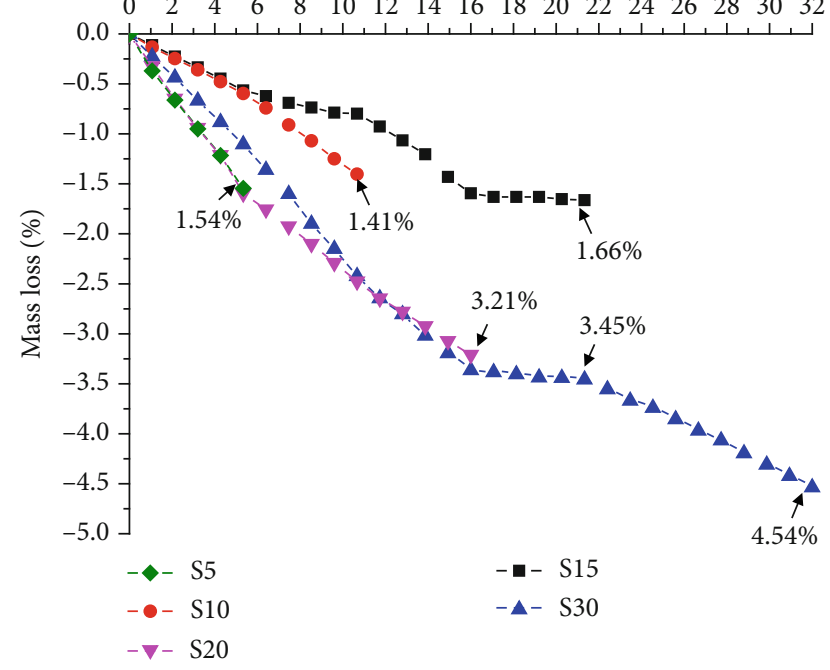

FIgURE 5: Sandstone specimen mass loss rate.

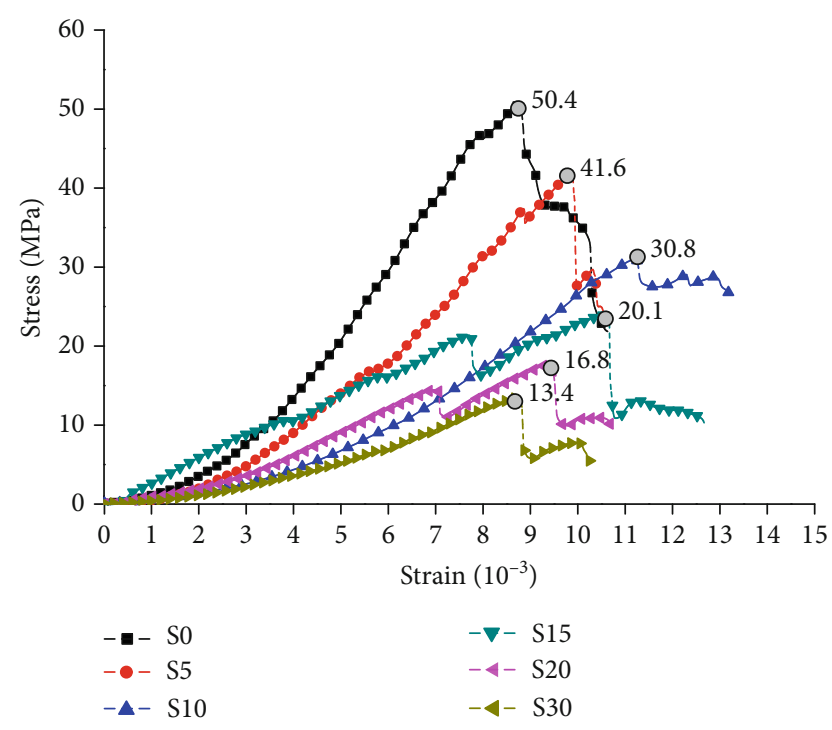

FIGURE 6: Stress-strain curves of sandstones with different salt damage erosion cycles.

between $0.1 \mathrm{~mm}$ and $0.2 \mathrm{~mm}$. The size of the numerical model is consistent with the indoor test size, set to $50 \mathrm{~mm}$ $\times 100 \mathrm{~mm}$. The particle density was $\rho=2560 \mathrm{~kg} / \mathrm{m}^{3}$, and the porosity was set to $n=0.12$. To simulate the spatial combination structural characteristics of irregular mineral particles in the sample and consider the self-locking effect between particles in the calculation process, this work adopts the flat-join contact model (plane bonding contact model). The model simulates the contact characteristics of irregular mineral particles by establishing a straight abstract interface between two round particles.

Based on the results obtained in the above indoor salt erosion test, the main body destroyed in the salt damage crystal erosion process was the interparticle cementation of the sample. As shown in Table 2, the strength parameters corre- sponding to the change attenuation in the PFC2D calculation were the elastic modulus (emod), cohesive strength (fj_cohesion), and tensile strength (fj_tension), of which most sensitive to the erosion process was the cohesive strength. The damage effect of the crystal particles was negligible, and the internal friction angle (fj_fric) can be considered to be relatively constant [30-32]. Based on the above understanding, the simulation path was set as

(1) First, the elastic modulus, tensile strength, and internal friction angle obtained in the S0 group test were used as the particle calculation parameters, and the compressive strength was used as a reference. Through a lot of trial calculations, the cohesion strength (fj_cohesion) parameters required by the model were calibrated with the compressive strength

(2) Next, the elastic modulus, tensile strength, and internal friction angle obtained from each group of the indoor tests were used as the particle calculation parameters, and the $\mathrm{S} 0$ group cohesive strength ( $\mathrm{fj}_{-}$ cohesion) parameter obtained in the process of (1) was used as the initial value. Taking the compressive strength fitting curve obtained in the indoor erosion test as the basic attenuation formula, the prediction function transformed into the cohesive strength by changing the initial value as follows:

$$
C_{n}=27.053 e^{-0.049 n}
$$

By substituting $n=0 / 5 / 10 / 15 / 20 / 30$ into equation (2), the cohesive strength calculation parameters of each group of samples were obtained. The numerical simulation calculation parameters are presented in Table 3:

3.2. Result Analysis. Table 4 displays the comparison between the compressive strength test value and the simulation value. The simulation results of the meso-parameters selected for the particle flow numerical simulation were relatively close to the macrotest results. The maximum relative error was $7.71 \%$ while the minimum error was $-2.15 \%$. These results show that the simulation scheme and calculation method were feasible. The inversion of uniaxial test parameters was achieved, and the construction of numerical simulation uniaxial test parameters under different salt erosion cycles was realized.

Figure 8 presents the numerical simulation uniaxial test curve under different salt erosion. The strain stroke was quite different from the indoor test. This is because the numerical model had reached the compact state in the initial state and could not simulate the initial compaction stage. The results of the numerical model lack the strain produced in the compaction stage.

Figure 9 shows the distribution of "displacement-force chain-crack" of sample particles under different salt erosion cycles. The figure displays the microscopic changes of the sample under peak stress conditions. The specific regulations are summarized as follows: (1) the particle displacement characteristics of the sample under different salt erosion 
TABLE 2: Results of sandstone mechanical parameters after different erosion cycles.

\begin{tabular}{lcccccccc}
\hline Erosion cycle/T & 0 & 5 & 10 & 15 & 20 & 30 & Fitting relationship & Fitting coefficient \\
\hline Compressive strength/MPa & 50.42 & 41.93 & 30.99 & 23.92 & 17.67 & 13.39 & $\sigma_{c}=51.15 e^{-0.049 n}$ & 0.99 \\
Elastic modulus/GPa & 8.41 & 6.84 & 4.62 & 3.01 & 2.93 & 2.50 & $E=8.4 e^{-0.053 n}$ & 0.94 \\
Tensile strength/MPa & 3.36 & 2.77 & 2.27 & 1.71 & 1.45 & 1.23 & $\sigma_{t}=3.3 e^{-0.039 n}$ & 0.98 \\
\hline
\end{tabular}

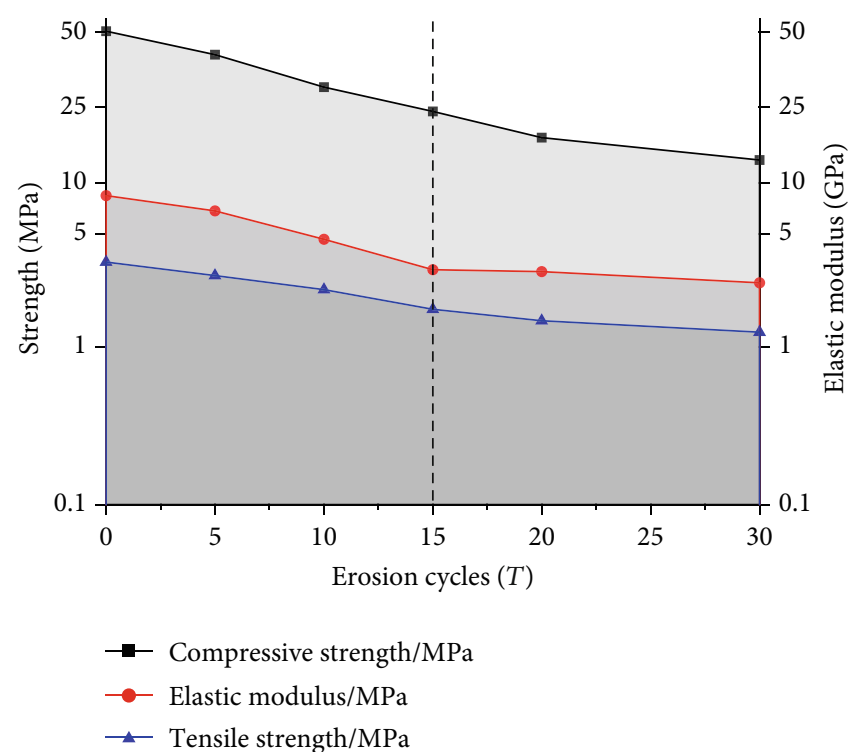

FIGURE 7: Variation of mechanical strength parameter attenuation under different erosion cycles.

TABLE 3: Numerical simulation meso-parameter table.

\begin{tabular}{lcccc}
\hline $\begin{array}{l}\text { Erosion } \\
\text { cycle/T }\end{array}$ & $\begin{array}{c}\text { Elastic } \\
\text { modulus/GPa }\end{array}$ & $\begin{array}{c}\mathrm{fj}_{-} \\
\text {tension/MPa }\end{array}$ & $\begin{array}{c}\mathrm{fj}_{-} \\
\text {cohesion/MPa }\end{array}$ & $\begin{array}{c}\left(\mathrm{fj}_{-}\right. \\
\text {fric }) /^{\circ}\end{array}$ \\
\hline 0 & 8.41 & 3.36 & 3.36 & 0.577 \\
5 & 6.84 & 2.77 & 2.77 & 0.577 \\
10 & 4.62 & 2.27 & 2.27 & 0.577 \\
15 & 3.01 & 1.71 & 1.71 & 0.577 \\
20 & 2.93 & 1.45 & 1.45 & 0.577 \\
30 & 2.50 & 1.23 & 1.23 & 0.577 \\
\hline
\end{tabular}

cycles are shown in Figure 9(a). With the increase in cycle erosion times, clear penetrating unilateral oblique cracks appeared when $T=0 / 5 / 10$. After $T=15 / 20 / 30$ cycles, the failure mode gradually changed to X-shaped. (2) The distribution characteristics of the force chains of the sample particles under different salt erosion cycles are shown in Figure 9(b). As the cyclic erosion times increased, the distribution characteristics of the force chains gradually evolved from regular distribution to disordered distribution. When $T=0 / 5 / 10 / 15$ times, the force chain peaks were concentrated around the penetrating oblique cracks. When $T=20 / 30$ times, the force chain peaks were distributed and concentrated in the unseparated fragments of the sample. (3) The distribution characteristics of sample cracks under different salt erosion cycles are shown in Figure 9(c). As the cyclic erosion times increased, the distribution and propagation of
TABLE 4: Comparison between uniaxial compression test value and PFC2D simulation value.

\begin{tabular}{lccc}
\hline $\begin{array}{l}\text { Erosion } \\
\text { cycle/T }\end{array}$ & $\begin{array}{c}\text { Compressive } \\
\text { strength test value } \\
\left(\sigma_{e}\right) / \mathrm{GPa}\end{array}$ & $\begin{array}{c}\text { Simulation value of } \\
\text { compressive strength } \\
\left(\sigma_{t}\right) / \mathrm{MPa}\end{array}$ & $\begin{array}{c}\text { Relative } \\
\text { error/\% }\end{array}$ \\
\hline 0 & 50.42 & 54.31 & 7.71 \\
5 & 41.93 & 41.027 & -2.15 \\
10 & 30.99 & 32.05 & 3.42 \\
15 & 23.92 & 24.91 & 4.14 \\
20 & 17.67 & 18.58 & 5.15 \\
30 & 13.39 & 13.03 & -2.68 \\
\hline
\end{tabular}

damage cracks also changed to a certain extent. When $T=$ 0/5/10/15 times, there was one penetration crack inside the sample, and other cracks developed at the edge of the sample. When $T=20 / 30$ times, there were two penetrating cracks inside the sample, which appeared crosswise in an X shape. The other cracks developed around the two main cracks. When the main and secondary cracks were closed, they were in a rhombus shape.

\section{Sandstone Salt Damage Evolution Analysis}

According to the test process, the sandstone damage can be divided into two parts. The first part is the periodic damage DT of sandstone under salt erosion, wherein the damage is primarily caused by the crystallization stress. The second part 


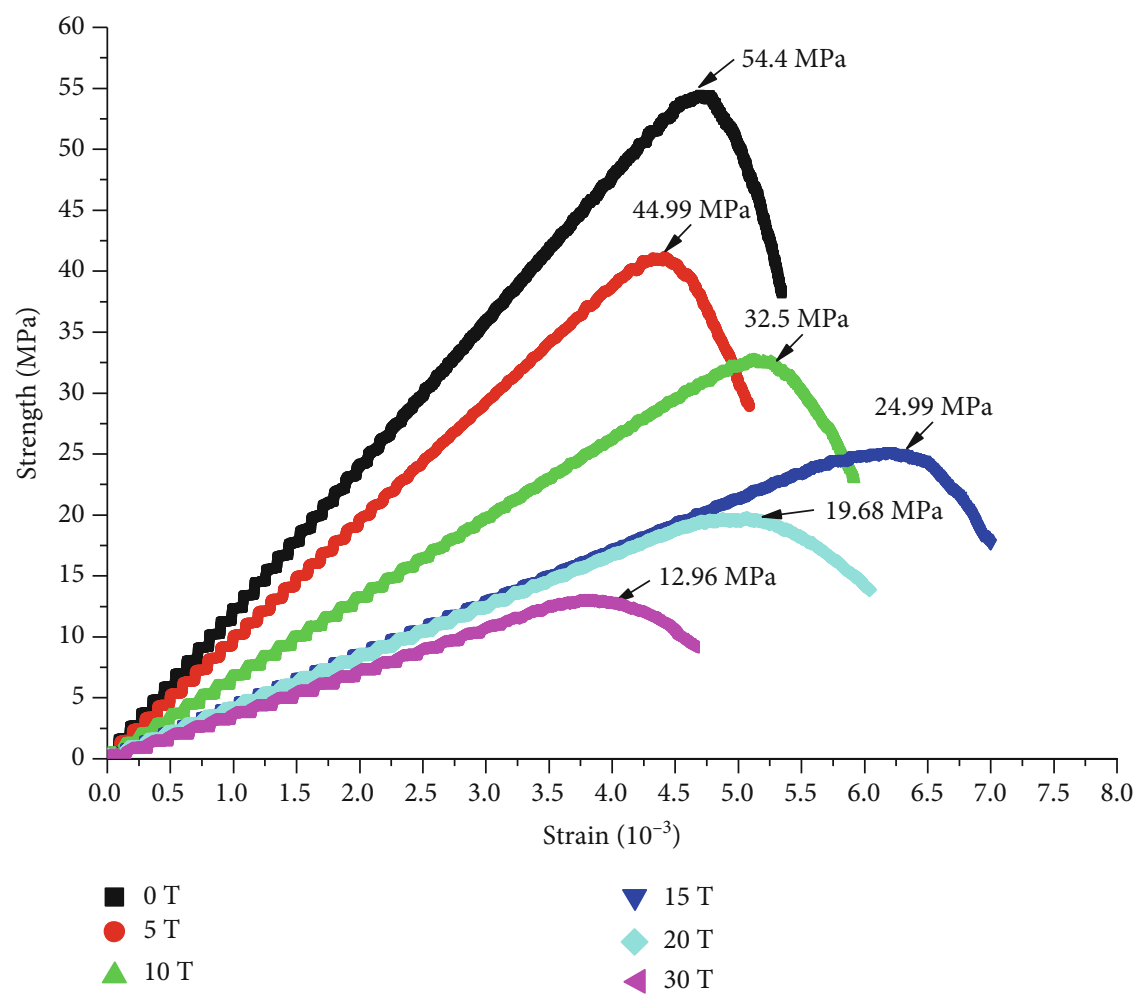

FIGURE 8: Numerical test results of mechanical strength attenuation under salt damage.

is the damage $\mathrm{D}$ caused by the uniaxial loading while measuring the macromechanical parameters of the sandstone. These two parts together caused the damage of the sandstone specimen. The total damage of sandstone can be solved according to the generalized strain equivalence principle proposed by Zhang et al.; in other words, during the test, the erosion damage of the first part and load damage of the second part affect each other. The effective stress generated by the erosion damage of the first part would have an effect on the strain of the second part of the load damage. The effective stress produced by the second part of the load damage would also act on the first part of the erosion damage strain. The strain influence values due to the two processes are equal. The traditional damage constitutive equation must be the elastic modulus of the lossless rock, which is difficult to measure, while the elastic modulus in the generalized strain equivalence principle is the rock with initial damage; hence, it has good applicability. Therefore, the damage constitutive model of the second part can be obtained as

$$
\sigma=E_{T}(1-D) \mathcal{\varepsilon}
$$

where $E_{T}$ is the linear elastic modulus of sandstone after cyclic damage, and $D$ is the load damage factor, which can be obtained according to the statistical damage model. And the first part of the erosion damage factor $D_{T}$ can be defined by selecting the linear elastic modulus as the damage variable:

$$
D_{T}=1-\frac{E_{T}}{E_{o}}
$$

In the formula, $E_{0}$ is the linear elastic modulus of sandstone under the initial damage state.

Substituting formula (4) into formula (3), two constitutive models of sandstone after damage can be obtained:

$$
\sigma=E_{o}\left(1-D_{T}-D+D_{T} D_{z}\right) \varepsilon
$$

The total loss of sandstone $D_{z}$ can be set and can be obtained by formula (5):

$$
D_{Z}=D_{T}+D-D_{T} D \text {. }
$$

The total damage of sandstone is not equal to the linear sum of erosion damage and load damage along with the joint damage item. As the strength of the rock material obeys the Weibull distribution, according to the meso-damage mechanics theory, the sandstone erosion damage evolution equation is:

$$
\begin{gathered}
D=\int_{o}^{\varepsilon} \phi(x) d x=1-e^{-1 / m\left(\varepsilon / \varepsilon_{c}\right) m}, \\
m=\frac{1}{\operatorname{In}\left(E_{o} \varepsilon_{c T} / \sigma_{c T}\right)} .
\end{gathered}
$$

In the formula, $\varepsilon_{c T}$ is the peak strain, $\sigma_{c T}$ is the corresponding peak stress, and $m$ is the material parameter that characterizes the evolution characteristics of material damage. 


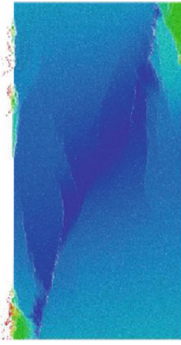

$T=0$

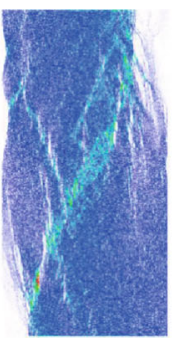

$T=0$

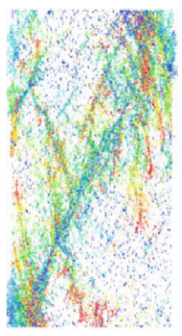

$T=0$

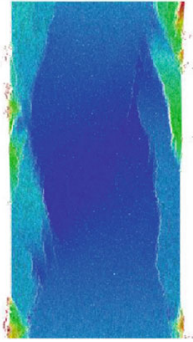

$T=5$

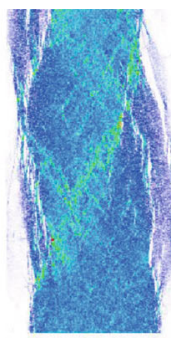

$T=5$

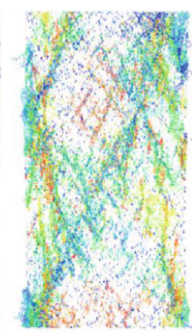

$T=5$

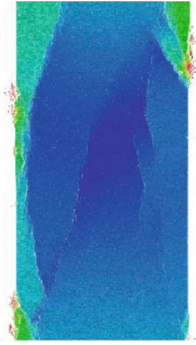

$T=10$

(a)

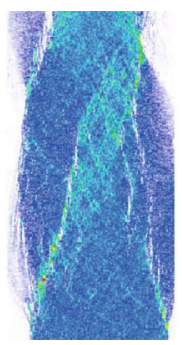

$$
T=10
$$

(b)

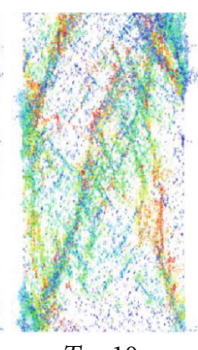

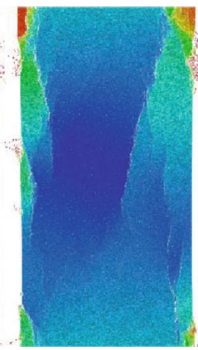

$T=15$

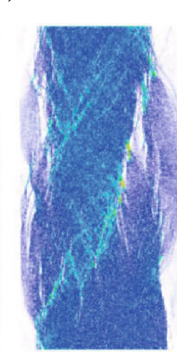

$T=15$

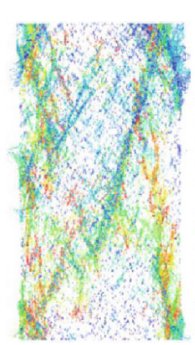

$T=15$

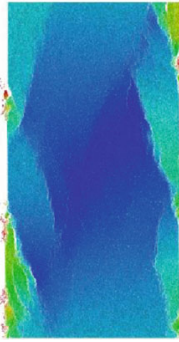

$T=20$

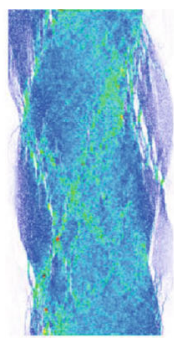

$T=20$

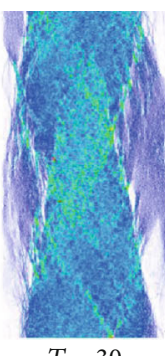

$T=30$

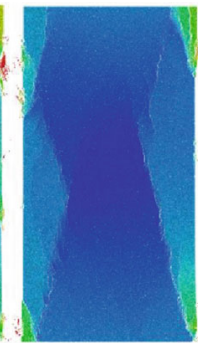

$T=30$

(c)

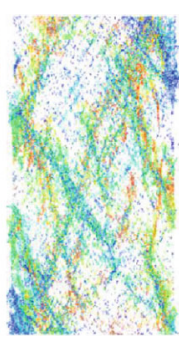

$T=20$

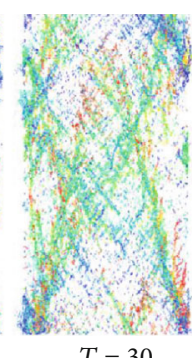

$T=30$

FIgURE 9: Distribution of sample particles “displacement-force chain-crack" under different salt damage erosion cycles. (a) Displacement distribution of sample particles under different salt erosion cycles. (b) Distribution of force chains of sample particles under different salt erosion cycles. (c) Distribution of sample particle cracks under different salt erosion cycles.

By substituting formula (4) and formula (7) into formula (6), the total damage evolution equation of sandstone becomes

$$
D_{z}=1-\frac{E_{T}}{E_{O}} e^{-1 / m\left(\varepsilon / \varepsilon_{c T}\right) m}
$$

As shown in Figure 10, using the macromechanical test data, the sandstone cyclic loading damage evolution curve was obtained.

When the strain was 0 , the sandstone was only damaged by the circulation of the erosion fluid. As the circulation period increased, the amount of erosion damage gradually amplified, and the damage of the $30 \mathrm{~T}$ sandstone reached 0.70 , which is a relatively large damage. Due to different erosion damages, the starting point of the load damage was also different, but the load damage increased with the rise in strain and gradually approached 1. In the initial stage of loading, the internal pores, cracks, and other defects of the sandstone were compacted and were

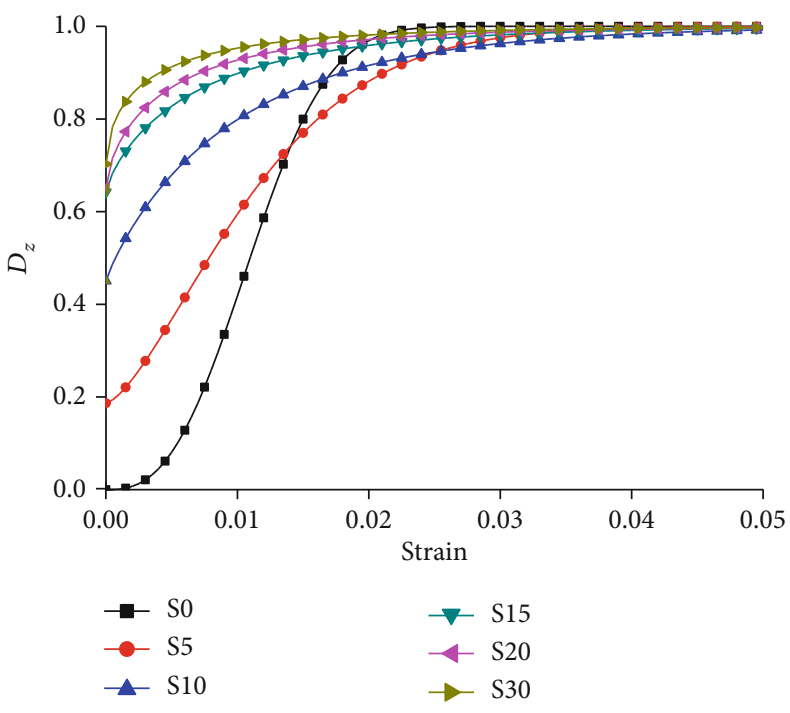

FIGURE 10: Evolution curve of load damage under sandstone cyclic erosion. 
in the compaction stage. As the strain increased, the specimen began to enter the elastic stage. At this time, the damage was at a low level. When the specimen entered the plastic strain stage, the damage began to accelerate until it failed, and the damage was 1. During the entire damage process, erosion damage was the basis of load damage and was affected by different cycles, impacting the development process of load damage.

\section{Conclusions}

(1) By conducting the salt damage cycle erosion test of Yungang sandstone, it is found that as the number of salt damage cycles increased, the surface roughness of the sandstone gradually amplified, and the phenomenon of sand loss gradually intensified. The mass loss rate of the test block was close to a linear increase, and there was no prominent slowing down within 30 cycles. By observing the erosion surface structure of sandstone under an optical microscope, the growth of $\mathrm{Na}_{2} \mathrm{SO}_{4}$ crystals in the pores of the sandstone produced crystallization stress. When the crystallization stress reached the strength of the cement, numerous microcracks were generated in the sandstone, causing the sand surface to fall off

(2) Through uniaxial compression tests under different salt damage cycles, it is found that the compressive strength, tensile strength, and elastic modulus of sandstone all lowered with the rise in the erosion cycle. The curve was divided into two stages. The compressive strength and elastic modulus of sandstone decreased rapidly before $15 \mathrm{~T}$, and the mechanical parameters decreased slowly after $15 \mathrm{~T}$

(3) Based on the sandstone salt erosion test data, a numerical simulation uniaxial test was established, which achieved the numerical simulation uniaxial test parameters under different salt erosion cycles. The distribution of "displacement-force chaincrack" of sandstone sample particles was analyzed, which further revealed the meso-fracture damage characteristics of Yungang Grotto sandstone under salt damage

(4) By establishing the erosion damage evolution equation of Yungang sandstone, the load damage of sandstone under different erosion cycles was analyzed. It was concluded that in the process of damage, erosion damage is the basis of load damage, which is affected by different cycles and impacts the development process of load damage

\section{Data Availability}

The data are available and explained in this article; readers can access the data supporting the conclusions of this study.

\section{Disclosure}

I would like to declare on behalf of my co-authors that the work described is original research and has not been previously published.

\section{Conflicts of Interest}

The authors declare no conflict of interest.

\section{Authors' Contributions}

The manuscript is approved by all authors for publication.

\section{Acknowledgments}

This work was supported by Research and development of object-oriented photogrammetry by UAV (Unmanned Aerial Vehicle) and rapid deployment monitoring and early warning equipment on high-steep slope (2019YFC1509604), Dazu District Science and Technology Commission Project Funding (Nos. DZKJ and 2018ABB1011), and the National Natural Science Foundation of China (NSFC) (41941018).

\section{References}

[1] M. Mariola, K. Dudek, and A. Gawe, "Cement render and mortar and their damages due to salt crystallization in the Holy Trinity Church, Dominicans Monastery in Cracow, Poland," Minerals, vol. 10, no. 7, p. 641, 2020.

[2] Y. Fujii, S. Saito, T. Oshima et al., "Complete slaking collapse of dike sandstones by fresh water and prevention of the collapse by salt water," International Journal of Rock Mechanics and Mining Sciences, vol. 131, article 104378, 2020.

[3] Z. Li, H. X. Liu, Z. L. Dun, L. W. Ren, and J. J. Fang, "Grouting effect on rock fracture using shear and seepage assessment," Construction and Building Materials, vol. 242, article 118131, 2020.

[4] D. W. Yin, S. J. Chen, Y. Ge, and R. Liu, "Mechanical properties of rock-coal bi-material samples with different lithologies under uniaxial loading," Journal of Materials Research and Technology, vol. 10, pp. 322-338, 2021.

[5] F. Nasri, A. Boumezbeur, and D. Benavente, "Influence of the petrophysical and durability properties of carbonate rocks on the deterioration of historic constructions in Tebessa (northeastern Algeria)," Bulletin of Engineering Geology \& the Environment, vol. 78, no. 6, pp. 3969-3981, 2019.

[6] J. Ma, X. Niu, C. Xiong et al., "Experimental investigation of the physical properties and microstructure of slate under wetting and drying cycles using micro-CT and ultrasonic wave velocity tests," Sensors, vol. 20, no. 17, article 485 3, 2020.

[7] Z. Zhou, X. Cai, D. Ma, L. Chen, S. Wang, and L. Tan, "Dynamic tensile properties of sandstone subjected to wetting and drying cycles," Construction \& Building Materials, vol. 182, pp. 215-232, 2018.

[8] S. J. Yan, Y. Fang, J. H. Liu, and S. E. Tan, "Deterioration experiment with soluble salt on sandstone of Yungang grottoes and its model creation," Rock and Soil Mechanics, vol. 34, no. 12 , pp. 3410-3417, 2013. 
[9] C. Chao, X. Pu, Z. Zhao, G. Wang, and H. Du, "Experimental Investigation on Wellbore Strengthening Based on a Hydraulic Fracturing Apparatus," Journal of Energy Resources Technology, vol. 140, no. 5, article 052902, 2018.

[10] M. Steiger, "Crystal growth in porous materials-I: the crystallization pressure of large crystals," Journalof Crystal Growth, vol. 282, no. 3-4, pp. 455-469, 2005.

[11] P. Theoulakis and A. Moropoulou, "Microstructural and mechanical parameters determining the susceptibility of porous building stones to salt decay," Construction and Building Materials, vol. 11, no. 1, pp. 65-71, 1997.

[12] Y. Q. Zhou, Q. Sheng, N. N. Li, and X. D. Fu, "Numerical analysis of the mechanical properties of rock materials under tiered and multi-level cyclic load regimesSoil Dynamics and Earthquake Engineering," vol. 135, Article ID 106186, 2020.

[13] D. Zhang, Y. Kang, A. P. S. Selvadurai, and L. You, "Experimental investigation of the effect of salt precipitation on the physical and mechanical properties of a tight sandstone," Rock Mechanics and Rock Engineering, vol. 53, no. 10, pp. 43674380, 2020.

[14] Q. Sun, Z. Dong, and H. Jia, "Decay of sandstone subjected to a combined action of repeated freezing-thawing and salt crystallization," Bulletin of Engineering Geology and the Environment, vol. 78, no. 8, pp. 5951-5964, 2019.

[15] X. Li, D. Qu, Y. Luo, R. Ma, K. Xu, and G. Wang, "Damage evolution model of sandstone under coupled chemical solution and freeze-thaw process," Cold Regions Science and Technology, vol. 162, pp. 88-95, 2019.

[16] Z. Li, S. G. Liu, W. T. Ren, J. J. Fang, Q. H. Zhu, and Z. L. Dun, "Multiscale laboratory study and numerical analysis of waterweakening effect on shale," Advances in Materials Science and Engineering, vol. 2020, Article ID 5263431, 14 pages, 2020.

[17] X. Wang, C. Liu, S. Chen, L. Chen, K. Li, and N. Liu, "Impact of coal sector's de-capacity policy on coal price," Applied Energy, vol. 265, article 114802, 2020.

[18] Q. Meng, H. Wang, M. Cai, W. Xu, X. Zhuang, and T. Rabczuk, "Three-dimensional mesoscale computational modeling of soil-rock mixtures with concave particles," Engineering Geology, vol. 277, article 105802, 2020.

[19] A. Hassanzadegan, G. Blöcher, H. Milsch, L. Urpi, and G. Zimmermann, "The effects of temperature and pressure on the porosity evolution of Flechtinger sandstone," Rock Mechanics \& Rock Engineering, vol. 47, no. 2, pp. 421-434, 2014.

[20] L. Shao, Study on rheological property of rockfill by mesomechanics simulation based on sub-critical crack expansion theory, Dalian University of Technology, 2013.

[21] L. Zhang, "Study on macro-meso damage characteristics of argillaceous sandstone under dry-wet cycle in acidic condition," Chongqing University, 2014.

[22] Z. G. Tao, C. Zhu, M. C. He, M. Karakus et al., “A physical modeling-based study on the control mechanisms of Negative Poisson's ratio anchor cable on the stratified toppling deformation of anti-inclined slopes," International Journal of Rock Mechanics and Mining Sciences, vol. 138, p. 104632, 2021.

[23] J. R. Williams and N. Rege, "The development of circulation cell structures in granular materials undergoing compression," Power Technology, vol. 90, pp. 187-194, 1997.

[24] C. Yi, Particle DEM Simulation for Rock Tests of Direct Tension and Compression, Southwest Jiaotong University, ChengDu, 2014.
[25] D. O. Potyondy, "A flat-jointed bonded-particle material for hard rock," in 46th U.S. Rock Mechanics/Geomechanics Symposium, Chicago, Illinois, 2012.

[26] D. K. Liu, Z. L. Gu, R. X. Liang et al., "Impacts of pore-throat system on fractal characterization of tight sandstones," Geofluids, vol. 2020, Article ID 4941501, 17 pages, 2020.

[27] H. Y. Pan, D. W. Yin, N. Jiang, and Z. G. Xia, "Crack initiation behaviors of granite specimens containing crossing-doubleflaws with different lengths under uniaxial loading," Advances in Civil Engineering, vol. 2020, Article ID 8871335, 13 pages, 2020.

[28] Q. X. Meng, H. L. Wang, W. Y. Xu, Y L. Chen, and P. Lin, "Numerical homogenization study on the effects of columnar jointed structure on the mechanical properties of rock mass," International Journal of Rock Mechanics and Mining Sciences, vol. 124, p. 104127, 2019.

[29] L. Yan, Q. X. Meng, W. Y. Xu et al., "A numerical method for analyzing the permeability of heterogeneous geomaterials based on digital image processing," Journal of Zhejiang University-SCIENCE A, vol. 18, no. 2, pp. 124-137, 2017.

[30] X. Zhang, Y. Wu, E. Zhai, P. Ye, and H. J. Zhou, "Coupling analysis of the heat-water dynamics and frozen depth in a seasonally frozen zone," Journal of Hydrology, vol. 593, p. 125603, 2021.

[31] G. Feng, X. C. Wang, M. Wang, and Y. Kang, "Experimental investigation of thermal cycling effect on fracture characteristics of granite in a geothermal-energy reservoir," Engineering Fracture Mechanics, vol. 235, p. 107180, 2020.

[32] C. Zhu, M. C. He, M. Karakus, X. B. Cui, and Z. G. Tao, "Investigating toppling failure mechanism of anti-dip layered slope due to excavation by physical modelling," Rock Mechanics and Rock Engineering, vol. 53, no. 11, pp. 5029-5050, 2020. 